\title{
Technological Evolution Agility and Dynamic IT Capabilities: A Delphi Study
}

\author{
Simon Bourdeau \\ UQAM \\ bourdeau.s@uqam.ca
}

\author{
Thibaut Coulon \\ UQAM \\ coulon.thibaut@uqam.ca
}

\author{
Dragos Vieru \\ TELUQ University \\ dragos.vieru@teluq.ca
}

\begin{abstract}
Robust information technology infrastructures (ITI) are essential for organizations since they are the heart of almost every organization and are considered as key assets that play strategic roles and affect organizational performance. To cope with the effects of technological evolution, IT managers must have an articulated vision of their ITI as well as the ability to acquire, deploy, combine and reconfigure their ITI, i.e. dynamic IT capabilities. However, the underlying organizational actions of dynamic IT capabilities are difficult to identify and to circumscribe. Drawing on a Delphi study involving 29 IT management experts, this study has identified key organizational actions deployed to overcome the challenges related to the constant and rapid technological evolution to be agile. Overall, the experts emphasized the importance of collaboration, open culture, competencies, roadmap, standardization and monitoring of ITI to overcome the challenges and exploit the opportunities related to the constant and rapid technological evolution while fostering organizational agility.
\end{abstract}

\section{Introduction}

Nowadays organizations are evolving in turbulent business environments. In such context, it is essential that organizations respond swiftly to opportunities resulting from and pressures imposed by their industries $[1,2]$. This situation is especially critical for IT infrastructures (ITIs) defined as an arrangement of shared IT services and technical components (e.g., platform, networks and communication, data, applications) [3,4], because of the compressed product life cycles, the growing number of IT outsourcing partnerships as well as the constant and rapid technological evolution [5-7].

Indeed, "technology shifts are among the most lethal threats to any successful business" [6, p. 525] and the development and management of ITIs are becoming more complex and uncertain [8]. As technologies are continuously and rapidly evolving, ITI are "always an unfinished work in progress" [8, p. 365]. Still, reliable ITIs are essential for organizations since they are the foundation of business applications and support both operational and strategic organizational activities [3]. As a central organizational asset, ITIs enable competitive performance and help organizations generate strategic advantages and organizational value $[7,9]$ Organizations modernize their ITI to have stable but flexible infrastructure to pursue various types of transformations [10].

To cope with rapid, uncertain and relentless technological evolution and changes, organizations must deploy organizational routines, i.e., "repetitive patterns of interdependent organizational actions" [11, p. 417], to exploit the opportunities triggered by these technological changes, while minimizing their threats and maintaining organizational agility $[2,12,13]$. Thus, IT managers must find the right balance between maintaining their existing ITI and developing/implementing new ITI components but also, between minimizing costs and maximizing ITI efficiency $[1,14,15]$.

Organizations must be agile by sensing and responding to these technological evolution and emerging technologies as they could affect their operations, their markets, their clients or change any element in their competitive environment [4, 15]. Organizational agility, which refers to an organization's capability to "detect opportunities and threats, assemble the needed assets and capabilities to launch an appropriate response, judge the benefits and risks of initiating an action, and execute actions with competitive speed and success" [15, p. 400], is vital for competitive success. Thus, organizational agility, which can be offensive, defensive or both, is contingent to internal or external threats and opportunities [15].

Even if no efforts should be spared by organizations to be agile [16], organizations are facing difficult decisions regarding their ITI and have to become tightrope walker to navigate between limiting ITI spending, streamlining ITI and developing/maintaining organizational agility $[1,17]$. As highlighted by Tallon et al. [1], organizations are constantly trying to balance between the "desire to be agile with an ongoing process to streamline IT operations and limit IT spending (p.2)". Due to constant technological evolution, the number of 
diverse IT components forming organizational ITI are continuously increasing, and managing an ITI has become the main concern for practitioners since it could potentially jeopardize an organization's agility $[2,18]$.

To cope with the effects of constant and rapidly evolving technologies on organizational agility, managers must have an articulated vision of their ITI as well as the ability to acquire, deploy, combine and reconfigure their ITI $[2,19]$. Such ability is needed to generate organizational value and sustain competitive advantage $[2,20]$, to support organizational agility [3, 19], and to deal with the challenges and opportunities triggered by constant and rapid technological evolution $[18,21]$. Thus, organizations must have dynamic IT capabilities to purposefully create, extend and modify their ITI to handle these challenges and opportunities as well as to maintain organizational agility $[13,15,22]$. The relations between ITI and organizational agility are rooted in the dynamic capability literature and focus on the ability of an organization to adapt, reconfigure or redeploy its IT resources according to internal or external threats or opportunities $[1,23]$.

It has been shown that dynamic IT capabilities influence organizational agility and performance [e.g., 2, 4, 19]. As dynamic capabilities "operate through a cluster of specific organizational actions working together to effect change" [13, p. 46], it could be assumed that specific organizational actions (OA) would be associated with dynamic IT capabilities. However, when looking at the various conceptualizations and operationalizations proposed in the literature [e.g., 19, 20], the underlying OA of the IT capability construct are difficult to identify and to circumscribe, especially OA focusing on the challenges and opportunities associated to the constant and rapid technological evolution. Identifying such OA could help practitioners better understand the way dynamic IT capabilities are developed, as well as how organizations cope and react to the technological evolution to be organizationally agile.

The study's objective is to identify the OA deployed to overcome the challenges related to the constant and rapid technological evolution to be agile. A Delphi study involving 29 ITI experts from two different sectors, i.e., private and public, was conducted. The outcomes of this study, a list of 20 OA (see Appendix 1) $)^{1}$, was analyzed by drawing on an IT capability theoretical perspective [19]. A discussion of the results followed by the presentation of the implications for both scholars and practitioners conclude the paper.

\footnotetext{
${ }^{1}$ The list of organizational challenges regarding technological evolution may be provided on demand.
}

\section{Dynamic IT capabilities and organizational agility}

IT capability was originally based on the resourcebased view perspective [13] and it was assumed that each organizational ITI was unique, valuable, rare and inimitable. According to this view, the idiosyncratic specificities of an ITI represent its strategic value. However, in today's world, as many components of ITIs are standardized, are becoming more of a commodity and are easily imitable, due especially to cloud computing solutions and IT outsourcing [24], IT capability is now conceptualized using a dynamic perspective [13]. In this view, dynamic IT capability represents an organization's ability to purposefully acquire, mobilize, deploy, combine and reconfigure its ITI. It can be defined as a latent construct comprised of three dimensions:

1. IT infrastructure capability, which represents an organization's “ability to deploy shareable platforms - a capability that captures the extent to which the firm is good at managing data management services and architectures, network communication services, and application portfolio and services" [19, p. 933];

2. IT business spanning capability which represents an organization's “ability to envision and exploit IT resources to support and enhance business objectives - a capability that reflects the extent to which the firm develops a clear IT strategic vision, integrates business and IT strategic planning, and enables management's ability to understand the value of IT investments (p. 935) and;

3. IT proactive stance, which represents an organization's “ability to proactively search for ways to embrace IT innovations or exploit existing IT resources to create business opportunities - a stance that measures the extent to which the firm always strives to be current with IT innovations, continues to experiment with new IT as necessary, constantly seeks new ways to enhance its effectiveness of IT use, and fosters a climate that is supportive of trying out new ways of using IT ( $p$. 935)".

An organization and its ITI will be considered agile when its IT capability allows the development, implementation, modification and/or maintenance of the ITI without creating important delays or engendering additional costs [20]. Roberts and Grover [3] have shown that the ITI enables organizations to sense and react to key elements in its environment and thus enhance organizational agility. Indeed, ITI provides the 
foundation for the integration and exploitation of new emerging technologies as well as for further digitalization of an organization's activities [2]. An ITI may impact an organization's performance by "deriving synergies with factors such as absorptive capacity, agility and market orientation" [7, p. 341].

Organizational agility is a higher-order dynamic capability that helps organizations to detect, react and adapt to contingencies arising from their environment, such as new regulations or new emerging technologies $[15,25]$. IT capacity is seen as a lower-order dynamic capability essential to organizational agility $[15,19]$. Organizational agility also relates to an organization's ability to access and use information resources to accommodate changes and shifts occurring in their environment [20]. Thus, the management and utilization of ITI is a key enabler of organizational agility.

While previous studies have highlighted the impact that IT capabilities have on organizational ability to detect and seize opportunities and threats [12], explanations and details regarding how, in terms of $\mathrm{OA}$ [13], these IT capabilities concretely impact agility and how organizations detect and react to emerging technologies and technological evolution, are scarce. Such explanations would help scholars better understand the organizational agility and the technological evolution phenomenon as well as help IT managers better identify and react to the threats and opportunities engendered by technological evolutions.

From both strategic and operational perspectives, it is important for IT managers to think in terms of IT capability when it comes to dealing with technological evolutions. Indeed, they should deploy OA, i.e., strategies and processes, to anticipate upcoming changes, respond to rapid technological evolution and maintain organizational agility $[2,12,13]$. Despite IT managers' intentions to change the way they manage their ITI and their concerns regarding the transformation of their ITI [26], there is a lack of studies that identified and circumscribed the OA deployed to deal with the challenges of emerging and evolving technologies to maintain organizational agility $[27,28]$.

\section{Methodology}

In order to identify the OA deployed by managers to deal with the challenges of emerging and evolving technologies to maintain organizational agility, a Delphi study was conducted with 29 ITI experts. The Delphi method allows a panel of experts to communicate and exchange, in an interactive and structured manner, to identify, select and categorize different ideas, such as

\footnotetext{
${ }^{2}$ Inter-rated reliability was calculated using Cohen's Kappa. A value
} of 0.79 was obtained, which can be interpreted as strong [34]. problems, key success factors or good practices [29-31]. This method was chosen over other methods such as surveys, focus group or case study, because of the complexity and scope of the phenomenon as well as the richness and breadth of information and knowledge provided by the experts. The main features of the Delphi method, 1) anonymity, 2) multiple iterations, 3) controlled feedback, and 4) statistical aggregation of group responses, make this identification method and ranking tool well suited for the intended research goal [29]. In the present study, we followed the methodological recommendations formulated by Delphi experts [e.g., 29, 30-33] (see appendix 2 for details).

Panel of expert - In terms of subject selection, choosing the appropriate experts may be one of the most important steps in the Delphi process as it is directly related to the quality of the results generated [29]. We followed Okoli \& Pawlowski's [33] and Paré et al.'s [29] recommendations concerning the procedure for the selection of experts. The experts are individuals, from private or public organizations, with knowledge and expertise in ITI management. We did not impose any restrictions on the geographic area in order to have a wide variety of viewpoints. Recruitment of the ITI experts was based on the authors' professional networks. A panel of 29 ITI experts was formed and divided into two groups of experts. Table 1 presents the main demographic data of the panel of experts.

Table 1. Demographics of experts in the Delphi Study

\begin{tabular}{|l|c|c|c|}
\hline \multicolumn{1}{|c|}{ Sectors } & Pub. & Pri. & Tot \\
\hline Nb. of respondents & 14 & 15 & $\mathbf{2 9}$ \\
\hline Age (avg.) & 48 & 48 & 48 \\
\hline Work experience (yrs.) & 25.3 & 23.3 & 24.3 \\
\hline IT experience (yrs.) & 19 & 18.2 & 18.6 \\
\hline
\end{tabular}

\section{Analysis and results}

During data collection, the OA identified by the experts were not classified in any category and experts were not asked to categorize them to avoid influencing their evaluations. However, since the study's objective was to identify a set of actions by which IT capability is enacted by organizations when facing the challenges of emerging and evolving technologies to maintain organizational agility, two of the authors categorized the $\mathrm{OA}$ in one of the three OA vectors ${ }^{2}$. Each vector reflects one of the three dimensions of the IT capability [19]: 1. IT business spanning capability, i.e. V1; 2. IT infrastructure capability, i.e. V2; 3 . IT proactive stance, i.e. V3. We conjecture that OA represent organizational strategies and processes that are deployed over a period of time with a certain "quantity" of efforts. These OA 
are also enacted and deployed with a "direction" in mind (i.e. to anticipate upcoming changes, respond to rapid technological evolution and maintain organizational agility). Thus, we surmise that the vector analogy is representative of a higher order concept to categorize the OA that has a magnitude and provides direction.

The OA categorized in one of the three vectors are somehow interrelated since they can either help managers co-design and guide the development and improvement of the enterprise architecture (vector \#1), support the deployment and management of the ITI (vector\#2), or help developing proactive technological culture, mindset, and competencies (vector \#3). These three vectors are complementary and we think that they would help organizations acquire, mobilize, deploy, and reconfigure their ITI to maintain their organizational agility.

Table 2 presents the results of the data collection where the most important OA are ranked, as identified by the experts from the private and public sectors. For each OA, the average scores of the ease of implementation evaluations are also presented in the last column.

Table 2. Ranking and grouping of organizational actions

\begin{tabular}{|c|c|c|c|c|}
\hline \multirow{2}{*}{\multicolumn{2}{|c|}{$\begin{array}{l}\text { Organizational actions to cope with the effects of technological evolution } \\
* \text { (Full descriptions of the organizational actions are provided in Appendix 1) }\end{array}$}} & \multicolumn{2}{|c|}{$\begin{array}{c}\text { Ranking per } \\
\text { group of experts }\end{array}$} & \multirow[t]{2}{*}{$\begin{array}{c}\text { Ease of } \\
\text { implementing }\end{array}$} \\
\hline & & Priv. & Pub. & \\
\hline ID* & \multicolumn{4}{|c|}{ Vector \#1 - Actions related to the Co-design and guidance of the enterprise architecture (V1) } \\
\hline A1 & Establish architectural teams & 1 & & 3.4 \\
\hline $\mathrm{C} 1$ & Develop collaboration between IT and business units & 3 & 2 & 2.9 \\
\hline A2 & Define life cycle and design a roadmap & 4 & & 3.4 \\
\hline S1 & Implement mechanisms for continuous improvement & 9 & 4 & 3.2 \\
\hline A3 & Define a corporate architecture framework & & 5 & 3.0 \\
\hline $\mathrm{S} 2$ & Assess internal and external technological risks & & 10 & 3.2 \\
\hline A4 & Create a committee for IT monitoring and prioritization & & 11 & 3.7 \\
\hline \multicolumn{5}{|c|}{ Vector \#2 - Actions related to the Deployment and management of the IT Infrastructure (V2) } \\
\hline T1 & Use of performance indicators to evaluate infrastructure performance & 2 & 8 & 3.4 \\
\hline $\mathrm{T} 2$ & Automate technological services in a standardized way & 6 & 12 & 2.6 \\
\hline $\mathrm{T} 3$ & Use of standards & 7 & 3 & 3.5 \\
\hline $\mathrm{T} 4$ & Migrate to cloud computing & 10 & & 3.2 \\
\hline T5 & Use of business and artificial intelligence & 12 & & 2.1 \\
\hline T6 & Adopt reliable and scalable technologies & & 1 & 2.9 \\
\hline $\mathrm{T} 7$ & Reuse of IT assets & & 13 & 2.9 \\
\hline \multicolumn{5}{|c|}{ Vector \#3 - Actions related to the Development of proactive technological culture, mindset and competencies (V3) } \\
\hline $\mathrm{C} 2$ & Create an organizational culture and implement a structure to foster technology watch & 5 & & 3.0 \\
\hline C3 & Use of external experts & 8 & & 4.0 \\
\hline E1 & Plan for continuous development skills & 11 & 9 & 3.1 \\
\hline E2 & Nurture an open mindset culture & 13 & 7 & 2.6 \\
\hline E3 & Establishment of working conditions favoring the retention of employees & & 6 & 2.9 \\
\hline S3 & Outsource & & 14 & 3.4 \\
\hline
\end{tabular}

The results in Table 2 show that all experts have identified similar strategies and processes to overcome the challenges to maintain organizational agility. Indeed, seven out of the 20 OA identified as important by the experts in terms of effectiveness are common to both group of experts, i.e. 1) Develop collaboration between IT and business units $(\mathrm{C} 1)$; 2) Implement mechanisms for continuous improvement (S1); 3) Use of performance indicators to evaluate infrastructure performance (T1); 4) Automate technological services in a standardized way (T2); 5) Use of standards (T3); 6) Plan for continuous development skills (E1) and ; 7) Nurture an open mindset culture (E2).

Data suggest that only the development of collaboration between the IT and the business units, an OA underlying the co-design and guidance of the enterprise architecture vector (V1) was ranked in the top three most effective actions by the experts in both groups.

Results also show some noticeable differences of perceptions among experts of the two sectors. For instance, Adopt reliable and scalable technologies (T6), Define a corporate architecture framework (A3) and Establish working conditions favoring the retention of employees (E3) were identified as important OA by public experts (ranked 1,5 and 6). The same OA were not identified as important by the private sector experts. On the opposite, while Establish architectural teams (A1), Define a life cycle and designing a roadmap (A2), and Create an 
organizational culture and implementing a structure to foster technology watch (C2) were listed amongst the five most important $\mathrm{OA}$ according to the private sector experts (ranked 1, 4 and 5), they were not identified as important by the experts from the public sector.

The data analysis also sheds light on the OA's ease of implementation. Indeed, some actions, such as Use of external experts (C3), Create a committee for IT monitoring and prioritization (A4), and Use of standards (T3) have been considered as being relatively easy to implement, while others, such as Use of business and artificial intelligence (T5), Automate technological services in a standardized way (T2), and Nurture an open mindset culture (E2), would require significant and sustained organizational efforts to be implemented.

\section{Discussion}

As we mentioned in the introduction, organizational agility facilitates an organization to create new practices of sensing, decision making, and reacting in timely and efficient manner to the environmental changes regarding their customers, technologies, competition, and regulations. Although extant studies have suggested IT as a key factor to achieve organizational agility, hasty investments in IT may limit organizations from fast and efficient sensing and reacting $[15,19]$. The outcomes of our study suggest that organizations may depend on IT to produce agility and confirm Lu and Ramamurthy's [19] findings that sensing and responding abilities of an organization require different types of IT capability enacted by complementary OA.

Our data analysis suggests that organizations may engage in different OA (see Table 2) to create IT capability for organizational agility to cope with the technological evolution and environmental change in accordance with different context-based organizational goals [19]. We conjecture that investing in different types of OA should be considered in supporting high-level organizational capabilities (i.e., organizational learning, innovation, etc.) because sensing and reacting abilities of an organization involve developing and deploying different types of OA [19].

Based on our data analysis, we also conjecture, that while IT capabilities [19] are concretely enacted by various OA, some of these OA have similar goals and nature. Thus, the nature of certain OA is more related to strategic aspects of ITI such collaboratively designing an architectural framework as well as guiding the deployment and management of ITI, i.e. V1. Other OA are more technologically focused and related to the exploitation or operationalization of the deployment and management of ITI, i.e. V2. Finally, some OA seems to be more human focused and related to the creation of a working environment that supports and fosters ITI exploration through competencies development, open mindset, and a technology watch culture, i.e. V3. As shown in Figure 1, the vectors are complementary. Moreover, Figure 1 shows that the results of an OA underlying one of the vectors serves as an input to the realization of the next vector, thus forming an iterative process. Therefore, the deployment of the OA must be done continuously while adapting to the changing context in which they are carried out.

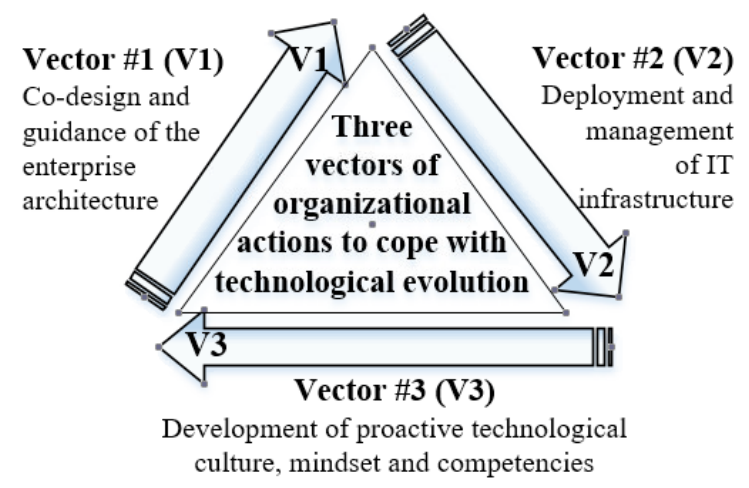

Figure 1. Coping successfully with the effects of

technological evolution span three vectors, each consisting of a specific set of organizational actions.

The results suggest that more than one third of the OA identified were categorized in the Deployment and management of ITI vector (V2) because they are related to the developing, implementing, monitoring and maintaining ITI services, data, and platforms. These results were not unexpected since IT managers have to perform technical changes to their ITI in terms of hardware, applications and/or data to overcome the challenges and to exploit the opportunities related to the constant and rapid technological evolution,. Thus, the results show that the ITI capability [19], which is concretely manifest itself by the OA underlying the Deployment and management of ITI vector (V2), is enacted by the use of performance indicators, the automation of technological services, the use of standards, the migration to cloud computing, the reliance on business and artificial intelligence as well as the adoption and reuse of reliable and scalable IT assets. These OA are related to some of the main concerns and intentions of IT executives regarding the management of their ITI as identified by Luftman et al. [34], such as partially moving their ITI to cloudbased services, investing in analytic/business intelligence, and monitoring ITI performance. 
In our Delphi study, seven other OA were also categorized under the Co-design and guidance of the enterprise architecture vector (V1), which reflects the IT business spanning capability [19]. These OA are related to an organization's IT strategic vision, role, orientations, and guidelines. The results show that this capability is enacted through the formation of architectural teams, closer collaboration between IT and business units, the creation of architecture frameworks, life cycle and roadmap as well as by the assessing, prioritizing and monitoring of ITI risks and evolution. From an organizational structure perspective, these OA are more strategic and should guide and support lower-level and operational decisions and actions related to ITI management.

Concerning the Development of proactive technological culture, mindset and competencies vector (V3), which is related to an organization's ability to be innovative, explore new ways of using IT and constantly try to enhance its ITI, six OA were identified. The results, which reflect IT proactive stance capability [19], show that this capability is enacted by relying on the expertise and experience of internal and/or external employees, the continuous improvement of their competences, as well as by developing a culture favoring openness, transparency, experimentation, and technological watch.

While the OA enacting the deployment and management of ITI vector (V2) are more technological-oriented and those enacting the codesign and guidance of the enterprise architecture vector (V1) are more strategically oriented, results suggest that the actions enacting the development of proactive technological culture, mindset and competencies vector (V3) are more human-oriented.

Overall, the experts emphasized the importance of collaboration, open culture, competencies, roadmap, standardization and monitoring of ITI to overcome the challenges and exploit the opportunities related to the constant and rapid technological evolution. In terms of collaboration, the experts stressed the importance of the links between IT managers and business units. For them, collaborating with users, business units, and decision makers would enable them to: a) identify their real needs and expectations (and not only those requested); b) develop a common strategy; c) maintain an adequate alignment of the evolving efforts; d) develop and test new functions; e) share knowledge and realities between IT and business units. The experts also agreed on the importance for promoting an open, explorative and flexible culture with respect to the management of the ITI. At the technological level, the use of standards should facilitate the interoperability of ITI components and ease the integration of emerging technologies. Also, a rigorous monitorization of the current ITI would make it possible to identify the components to be replaced. Moreover, establishing mechanisms for continuous improvement of the ITI is a key for improving, simplifying, and anticipating technological evolution. Further, it is interesting to note that the four most important OA for private sector experts, in terms of effectiveness (see table 2), are not technologicaloriented actions but rather process-oriented actions [35].

Several differences emerged between the responses of the two groups of experts. The organizational action that seems to be the most important for the public sector experts, i.e., Adopt reliable and scalable technologies (4), is mainly operational and has not been identified by private sector experts. Focusing on such "operational" action can be explained by challenges faced by public organizations in recruiting, retraining, and retaining IT employees. Indeed, as most public sector organizations are facing a shortage of IT employees, IT managers might be more preoccupied by short-term demands and operational challenges rather than developing a clear long-term strategic vision of their IIT. Without these shortages, it would probably be more efficient for an organization to have competent employees who are able to adapt to new emerging technologies, rather than rely on evolutive technologies and hoping that these technologies will help them to adapt and respond to the technological evolution. Moreover, the public sector experts also highlighted the importance of outsourcing, planning the ongoing development of skills, and creating working conditions that favor the retention of employees.

The experts in the private sector insisted on the importance of establishing architectural teams, which involves not only the creation of an "operating architecture" team responsible for determining the products/services/methods to put in place, but also a "business architecture" team responsible for establishing the enterprise architecture framework. Further, while the migration to the cloud is an organizational action that was not considered important in the public sector, it was deemed important by the experts in the private sector. Such organizational action is intended to improve flexibility, enable responses to unanticipated high demands, ease the scalability of the ITI, and avoid inhouse management and development of the ITI. Finally, the private sector experts recommended the establishment of a technological watch culture and structures to continually monitor technological developments, changing practices, and assess their relevance. 
Both scholars and practitioners should be cautious when interpreting the rankings of the OA identified in the present study. The rankings in Table 2 were compiled based on their anticipated effectiveness. However, these actions should also be interpreted by taking into consideration their ease of implementation, as some highly ranked actions might require extensive efforts to deploy. Thus, it might be wiser for IT managers to first focus on OA which are easier to implement in order to have "quick wins" and create an organizational momentum.

From a practitioner's point of view, the study aims at helping IT managers to: 1 . better react when confronted with new emerging technologies; 2. learn how their colleagues from other sectors adopt and implement various OA to face technological evolution and better manage their ITI. The results should also help public sector officials to identify cross-sectoral differences with private sector organizations and help them eventually better collaborate with private sector partners.

\section{Conclusion}

While IT infrastructures are developed and expanded over a long period, IT managers must deploy $\mathrm{OA}$ to overcome the challenges and exploit the opportunities related to the constant and rapid technological evolution. Based on the input of 29 ITI management experts, this study has identified key OA deployed by organizations to deal with new emerging technologies and maintain organizational agility. These OA, which have been grouped into three vectors: Co-design and guidance of the enterprise architecture (V1),Deployment and management of the IT Infrastructure (V2), and Development of proactive technological culture, mindset and competencies (V3). These vectors reflect the three dimensions IT capability [19] and each one represent the cluster of specific OA through which IT capabilities are enacted. We hope that this study's results study will guide and support practitioners in their decision-making processes as well as help scholars in their exploration of issues related to IT capability, technological evolution and the management of IT infrastructures.

\section{References}

[1] Tallon, P.P., Queiroz, M., Coltman, T., and Sharma, R., "Information technology and the search for organizational agility: A systematic review with future research possibilities", Journal of Strategic Information Systems, 2019, 28, (2), pp. 218-237.

[2] Ravichandran, T., "Exploring the relationships between IT competence, innovation capacity and organizational agility", The Journal of Strategic Information Systems, 2018, 27, (1), pp. 22-42.

[3] Roberts, N., and Grover, V., "Leveraging information technology infrastructure to facilitate a firm's customer agility and competitive activity: An empirical investigation", Journal of Management Information Systems, 2012, 28, (4), pp. 231-270.

[4] Chakravarty, A., Grewal, R., and Sambamurthy, V., "Information technology competencies, organizational agility, and firm performance: Enabling and facilitating roles”, Information systems research, 2013, 24, (4), pp. 976997

[5] Gatignon, H., Gotteland, D., and Haon, C., "Assessing Innovations from the Technology Perspective": "Making Innovation Last: Volume 1' (Springer, 2016), pp. 19-51

[6] Tongur, S., and Engwall, M., "The business model dilemma of technology shifts", Technovation, 2014, 34, (9), pp. 525-535.

[7] Bhatt, G., Emdad, A., Roberts, N., and Grover, V., "Building and leveraging information in dynamic environments: The role of IT infrastructure flexibility as enabler of organizational responsiveness and competitive advantage", Information \& Management, 2010, 47, (7-8), pp. 341-349.

[8] Edwards, P.N., Bowker, G.C., Jackson, S.J., and Williams, R., "Introduction: an agenda for infrastructure studies", Journal of the Association for Information Systems, 2009, 10, (5), pp. 6.

[9] Piccoli, G., and Lui, T.-W., "The competitive impact of information technology: can commodity IT contribute to competitive performance?", European Journal of Information Systems, 2014, 23, (6), pp. 616-628.

[10] Dhasarathy, A., Gill, I., Khan, N., Sekar, S., and Van Kuiken, S., "How to become 'tech forward': A technologytransformation approach that works ", McKinsey \& Company, 2020, pp. 7.

[11] Parmigiani, A., and Howard-Grenville, J., "Routines revisited: Exploring the capabilities and practice perspectives", Academy of Management annals, 2011, 5, (1), pp. 413-453.

[12] Sambamurthy, V., Bharadwaj, A., and Grover, V., "Shaping agility through digital options: Reconceptualizing the role of information technology in contemporary firms", MIS quarterly, 2003, pp. 237-263.

[13] Yeow, A., Soh, C., and Hansen, R., "Aligning with new digital strategy: A dynamic capabilities approach", The Journal of Strategic Information Systems, 2018, 27, (1), pp. 43-58.

[14] Andriopoulos, C., and Lewis, M.W., "Exploitationexploration tensions and organizational ambidexterity: Managing paradoxes of innovation", Organization science, 2009, 20, (4), pp. 696-717.

[15] Lee, O.-K., Sambamurthy, V., Lim, K.H., and Wei, K.K., "How does IT ambidexterity impact organizational agility?", Information Systems Research, 2015, 26, (2), pp. 398-417.

[16] Teece, D.J., Peteraf, M., and Leih, S., "Dynamic capabilities and organizational agility: Risk, uncertainty, and strategy in the innovation economy", California Management Review, 2016, 58, (4), pp. 13-35. 
[17] Kappelman, L., Johnson, V., Torres, R., Maurer, C., and McLean, E., "A study of information systems issues, practices, and leadership in Europe", European Journal of Information Systems, 2019, 28, (1), pp. 26-42.

[18] Hernantes, J., Gallardo, G., and Serrano, N., "IT infrastructure-monitoring tools", IEEE Software, 2015, 32, (4), pp. 88-93.

[19] Lu, Y., and Ramamurthy, K., "Understanding the link between information technology capability and organizational agility: An empirical examination", MIS Quarterly, 2011, pp. 931-954.

[20] Fink, L., and Neumann, S., "Gaining Agility through IT Personnel Capabilities: The Mediating Role of IT Infrastructure Capabilities", Journal of the Association for Information Systems, 2007, 8, (8), pp. 440-462.

[21] Briggs, B., \& Buchhols, S., "Tech Trends 2019. Beyond the digital frontier. Deloitte Insights, 2019, pp.90.

[22] Li, T.C., and Chan, Y.E., "Dynamic information technology capability: Concept definition and framework development", The Journal of Strategic Information Systems, 2019, 28, (4), pp. 1-20.

[23] Overby, E., Bharadwaj, A., and Sambamurthy, V., "Enterprise agility and the enabling role of information technology", European Journal of Information Systems, 2006, 15, (2), pp. 120-131.

[24] Zardini, A., Rossignoli, C., and Ricciardi, F., "A bottom-up path for IT management success: From infrastructure quality to competitive excellence", Journal of Business Research, 2016, 69, (5), pp. 1747-1752.

[25] Tallon, P.P., and Pinsonneault, A., "Competing perspectives on the link between strategic information technology alignment and organizational agility: insights from a mediation model", MIS Quarterly, 2011, pp. 463-486 [26] Vial, G., "Understanding digital transformation: A review and a research agenda", The Journal of Strategic Information Systems, 2019.

[27] Tilson, D., Lyytinen, K., and Sorense, C., "Research Commentary - Digital Infrastructures: The Missing IS Research Agenda", Information Systems Research, 2010, 21, (4), pp. 748-759.

[28] Tallon, P.P., Queiroz, M., Coltman, T., and Sharma, R., "Information technology and the search for organizational agility: A systematic review with future research possibilities", The Journal of Strategic Information Systems, 2018.

[29] Paré, G., Cameron, A.-F., Poba-Nzaou, P., and Templier, M., "A systematic assessment of rigor in information systems ranking-type Delphi studies", Information \& Management, 2013, 50, (5), pp. 207.

[30] Rowe, G., and Wright, G., "The Delphi technique as a forecasting tool: issues and analysis", International journal of forecasting, 1999, 15, (4), pp. 353-375.

[31] Schmidt, R.C., "Managing Delphi surveys using nonparametric statistical techniques", decision Sciences, 1997, 28, (3), pp. 763-774.

[32] El-Gazzar, R., Hustad, E., and Olsen, D.H., "Understanding cloud computing adoption issues: A Delphi study approach", Journal of Systems and Software, 2016, 118, pp. 64-84.

[33] Okoli, C., and Pawlowski, S.D., "The Delphi method as a research tool: an example, design considerations and applications", Information \& management, 2004, 42, (1), pp. 15-29.

[34] Luftman, J., Derksen, B., Dwivedi, R., Santana, M., Zadeh, H., and Rigoni, E., "Influential IT management trends: an international study", Journal of Information Technology, suppl. Special Issue: Mobile Platforms and Ecosystems, 2015, 30, (3), pp. 293-305.

[35] Fink, L., and Neumann, S., "Exploring the perceived business value of the flexibility enabled by information technology infrastructure", Information \& Management, 2009, 46, (2), pp. 90-99.

[36] Kendall, M., and Gibbons, J., "Rank Correlation Methods", Oxford University Press, 1990.

[37] Cafiso, S., Di Graziano, A., and Pappalardo, G., "Using the Delphi method to evaluate opinions of public transport managers on bus safety", Safety science, 2013, 57, pp. 254263.

[38] Siegel, S., and Castellan, N.J.J., "Nonparametric Statistics for the Behavioral Sciences", Wiley, 2nd edn., 1988).

\section{Appendix 1 - Organizational Actions}

\begin{tabular}{|c|c|c|}
\hline ID & Labels & Descriptions \\
\hline \multicolumn{3}{|r|}{ Category \#1 -ARCHITECTURE-related organizational actions - (A) } \\
\hline A1 & $\begin{array}{l}\text { Establish architectural } \\
\text { teams }\end{array}$ & $\begin{array}{l}\text { Creation of a "business architecture" team responsible for establishing the enterprise architecture framework, } \\
\text { (i.e. determining standards and guidelines) and an "operating architecture" team responsible for determining } \\
\text { - based on the AE -, the products / services / methods to put in place a roadmap based on the various major } \\
\text { areas of the technological infrastructure. }\end{array}$ \\
\hline A2 & $\begin{array}{l}\text { Define life cycle and } \\
\text { design a roadmap }\end{array}$ & $\begin{array}{l}\text { Define the life cycle of the components of the technological infrastructure and design a road map of future } \\
\text { components replacement to anticipate technological developments and investments, optimize technological } \\
\text { changes, adapt these technological evolutions to the organizational environment and avoid obsolescence. }\end{array}$ \\
\hline A3 & $\begin{array}{l}\text { Define a corporate } \\
\text { architecture } \\
\text { framework }\end{array}$ & $\begin{array}{l}\text { Define an enterprise architecture framework and evaluate all elements of this architecture, i.e. processes, } \\
\text { data, technologies, applications, services, standards, structures, etc. to meet organization's business } \\
\text { objectives, guide transformation, and sustainably manage technological changes and infrastructure. }\end{array}$ \\
\hline A4 & $\begin{array}{l}\text { Create a committee } \\
\text { for IT monitoring and } \\
\text { prioritization }\end{array}$ & $\begin{array}{l}\text { Creating a committee to identify and monitor technology needs, technological change and technology } \\
\text { advancement to align with the organization's enterprise architecture framework and to raise organization's } \\
\text { awareness of technological infrastructure's roles. }\end{array}$ \\
\hline
\end{tabular}




\begin{tabular}{|c|c|c|}
\hline \multicolumn{3}{|r|}{ Category \#2 - COLLABORATION-related organizational actions - (C) } \\
\hline $\mathrm{C} 1$ & $\begin{array}{l}\text { Develop collaboration } \\
\text { between IT and } \\
\text { business units }\end{array}$ & $\begin{array}{l}\text { Collaborate regularly with users, business units and internal decision-makers to identify and clarify their } \\
\text { needs and expectations, develop a common strategy, maintain appropriate alignment of evolution efforts, } \\
\text { develop and test new functions, share knowledge, etc. }\end{array}$ \\
\hline $\mathrm{C} 2$ & $\begin{array}{l}\text { Create an } \\
\text { organizational culture } \\
\text { and implement a } \\
\text { structure to foster } \\
\text { technology watch }\end{array}$ & $\begin{array}{l}\text { Establish a technology watch culture and structure to continually monitor technological developments; } \\
\text { changing practices, trends, ways of doing things, assessing their relevance to the organization; to anticipate } \\
\text { and prepare for technological challenges, etc. }\end{array}$ \\
\hline $\mathrm{C} 3$ & Use of external experts & $\begin{array}{l}\text { Use external experts / consultants to gain access to new knowledge, assist the organization in planning the } \\
\text { evolution of the technology infrastructure, have expert assistance to make specific IT choices, facilitate } \\
\text { digital transformations, have an external evaluation of the internal work practices. }\end{array}$ \\
\hline \multicolumn{3}{|r|}{ Category \#3 - EMPLOYEES-related organizational actions - (E) } \\
\hline E1 & $\begin{array}{l}\text { Plan for continuous } \\
\text { development skills }\end{array}$ & $\begin{array}{l}\text { Plan the development of employees' IT skills on an ongoing basis by offering coaching, involving them in } \\
\text { internal training, sending them to seminars, etc. to ensure up-to-date skills, cope with the emergency of new } \\
\text { technologies and enable technological change readiness. }\end{array}$ \\
\hline E2 & $\begin{array}{l}\text { Nurture an open } \\
\text { mindset culture }\end{array}$ & $\begin{array}{l}\text { Promote an organizational culture of open mindset with regard to the management of technology } \\
\text { infrastructure and IT in general in the organization. }\end{array}$ \\
\hline E3 & $\begin{array}{l}\text { Establishment of } \\
\text { working conditions } \\
\text { favoring the retention } \\
\text { of employees }\end{array}$ & $\begin{array}{l}\text { Create working conditions that encourage retention, collaboration and knowledge sharing between } \\
\text { employees in order to cope with technological developments, such as appointing a "Chief happiness officer", } \\
\text { promote the reconciliation work-private life, etc. It is also important to assess and manage the risks related to } \\
\text { employee frustration that that stem from factors such as changing assignments, perceived cumbersome } \\
\text { bureaucracy, etc. }\end{array}$ \\
\hline \multicolumn{3}{|r|}{ Category \#4 - TECHNOLOGY-related organizational actions - (T) } \\
\hline $\mathrm{T} 1$ & $\begin{array}{l}\text { Use of performance } \\
\text { indicators to evaluate } \\
\text { infrastructure } \\
\text { performance }\end{array}$ & $\begin{array}{l}\text { Develop and use indicators to assess the performance of the components of the technology infrastructure, } \\
\text { i.e., costs, volume, downtime, maintenance, etc. and thus identify the components to be replaced. }\end{array}$ \\
\hline $\mathrm{T} 2$ & $\begin{array}{l}\text { Automate } \\
\text { technological services } \\
\text { in a standardized way }\end{array}$ & $\begin{array}{l}\text { Automate technological services using market standards (i.e., SDDC, Software-defined data center) to } \\
\text { separate organizational processes from technological infrastructures and thus promote the evolution of } \\
\text { infrastructure by minimizing the impacts on the organizational processes. }\end{array}$ \\
\hline $\mathrm{T} 3$ & Use of standards & $\begin{array}{l}\text { Promote the use of standards when acquiring, developing and maintaining technological infrastructures in } \\
\text { order to standardize practices, facilitate the interoperability of systems and ease the integration of emerging } \\
\text { technologies }\end{array}$ \\
\hline $\mathrm{T} 4$ & $\begin{array}{l}\text { Migrate to cloud } \\
\text { computing }\end{array}$ & $\begin{array}{l}\text { Migrate "on-premise" systems to cloud computing platforms in order to have greater flexibility, to respond } \\
\text { to unanticipated high demands, to ease the scalability of systems, avoid in-house the management of systems } \\
\text { development. }\end{array}$ \\
\hline T5 & $\begin{array}{l}\text { Use of business and } \\
\text { artificial intelligence }\end{array}$ & $\begin{array}{l}\text { Use artificial intelligence tools, such as machine learning, to exploit the data generated by technological } \\
\text { infrastructure (e.g. energy consumption, speed, number of errors, etc.) and thus be better prepared to cope } \\
\text { with technological change. }\end{array}$ \\
\hline T6 & $\begin{array}{l}\text { Adopt reliable and } \\
\text { evolutive technologies }\end{array}$ & $\begin{array}{l}\text { Adopt components in the technology infrastructure that are "flexible" and scalable, for example, components } \\
\text { that can be updated, enhanced and / or extended; promote open standards and cloud computing; continuously } \\
\text { test and adopt new components, etc. }\end{array}$ \\
\hline $\mathrm{T} 7$ & Reuse of IT assets & $\begin{array}{l}\text { Reuse and adapt, where possible, existing technological infrastructure components when implementing } \\
\text { technological innovations to optimize the use of existing technological resources. }\end{array}$ \\
\hline \multicolumn{3}{|r|}{ Category \#5-STRATEGIC-related organizational actions - (S) } \\
\hline $\mathrm{S} 1$ & $\begin{array}{l}\text { Implement } \\
\text { mechanisms for } \\
\text { continuous } \\
\text { improvement }\end{array}$ & $\begin{array}{l}\text { Establish mechanisms for continuous improvement of the technological infrastructure in order to improve, } \\
\text { simplify, and anticipate technological developments, i.e., conducting recurrent technological infrastructure } \\
\text { evaluation by having an interdisciplinary monitoring committee. }\end{array}$ \\
\hline $\mathrm{S} 2$ & $\begin{array}{l}\text { Assess internal and } \\
\text { external technological } \\
\text { risks }\end{array}$ & $\begin{array}{l}\text { Evaluate the probability of technology risks (internal and external) and their potential impacts, to identify } \\
\text { Infrastructure components to be updated, extended or replaced, to mitigate those risks. }\end{array}$ \\
\hline S3 & Outsource & Engaging in outsourcing practices to take advantage of suppliers' expertise, innovation, and IT infrastructure. \\
\hline
\end{tabular}




\section{Appendix 2 - Methodology}

Step 1: Brainstorming - In the questionnaire used in Step 1, besides the demographics, the following question was proposed to the experts: What are the organizational actions (e.g., practices, routines, strategies) deployed by organizations to overcome the challenges and exploit the opportunities related to the constant and rapid technological evolution while fostering organizational agility

Respondents were required to provide at least 6 detailed responses. The questionnaire was pre-tested on three IT experts. A total of 198 different organizational actions (OA) were collected. The received data were compiled using Excel software. Experts' answers and explanations were analyzed first individually, and then collectively by the three authors. Analogous and overlapping responses were grouped under the same label and, for each label, a description was written based on the descriptions provided by the experts (42 labels were identified).

Validation - For this step, the ITI experts were contacted a second time to validate the list generated during the first part of the brainstorming step. First, experts had to validate the consolidated list of the 42 $\mathrm{OA}$ in terms of meaning and representativeness. The questionnaire provided spaces for the expert to comment and/or suggest changes or corrections to any of the labels or descriptions. Then, the experts were given the opportunity to add OA that they might have missed or forgot during the first round. Finally, they were asked to validate the researchers' interpretations of their answers in the first part of the brainstorming step. The experts' comments and suggestions provided during the validation step were analyzed and a final list of the OA was generated.

Step 2: Narrowing - In the second step, each respondent received the list of the $42 \mathrm{OA}$ and were asked to select the 10 most important ones based on their respective effectiveness, without ranking them. To avoid selection biases, the 42 actions were randomly ordered. The OA identified as important for each of the IT experts' group - private and public -, were treated separately. A preliminary analysis of the results in step 1 revealed some differences between the actions in terms of scope. For instance, some OA seemed relatively easy to implement, while others seemed to require important organizational transformations and efforts. Thus, in the second step, respondents were also asked to assess the ease of implementing the different OA on a scale of 1 to 5 (1 $=$ very difficult to implement and $5=$ very easy to implement) (see table 2).

The questionnaires received during the second step were analyzed by the three authors. A selection rule was established following the recommendations of Delphi experts $[29,33]$ and applied to narrow the list of the most important OA. The rule was that, in order to be selected, a specific action had to be identified by at least $40 \%$ of experts. A total of 20 actions were selected by at least one group of experts (see Appendix 1 for the final list of 20 actions).

Step 3: Ranking - For the final step, respondents received a list of the most important OA, as identified by the experts of their respective sectors during step 2 and were asked to rank them in order of the level of their effectiveness $(1=$ the most important/effective and $\mathrm{N}=$ the least important/effective).

Establishment of consensus - Following Paré et al.'s [29] recommendations, Kendall W coefficients were calculated [36] to establish the level of consensus between the participating experts regarding the ranking of the most important OA. It should be noted that a Kendall coefficient of $\mathrm{W}=1.0$ would mean that all the participating experts would perfectly agree with one another regarding the ranking of the OA [32]. According to Cafiso et al. [37], a consensus level W $<0.3$ is considered low, between 0.3 and 0.5 , it is considered moderate, between 0.5 and 0.7 it is considered good and greater than 0.7 is considered strong. Since all consensus coefficients (W) were less than 0.3 in the first round, a second-ranking round was conducted. In the second round, the experts received a list presenting the OA to be ranked accompanied by the average results obtained during the first ranking round. Table A2 shows that the consensus levels between the two rounds improved significantly.

Table A2. Kendall W coefficient level

\begin{tabular}{|l|c|c|}
\hline & \multicolumn{2}{|c|}{ Kendall's W } \\
\hline Panels & Round \#1 & Round \#2 \\
\hline Experts - Public & 0.13 & 0.54 \\
\hline Experts - Private & 0.19 & 0.51 \\
\hline
\end{tabular}

In the second round, the consensus coefficients of the ITIs experts of both the private and the public sectors are considered "good" because they are between 0.5 and 0.7" [37]. According to Cafiso et al. [37], caution is required when Kendall's (W) coefficients are interpreted using these guidelines since they are not meant to be used as exact break points. Moreover, the higher the number of elements on which Delphi's participants have to establish a consensus, the more difficult it is to have a good or strong consensus [36-38]. The consensus levels obtained in the present study seems adequate since the ITI experts had to develop a consensus on lists that contains between 13 and 15 items $[37,38]$. 